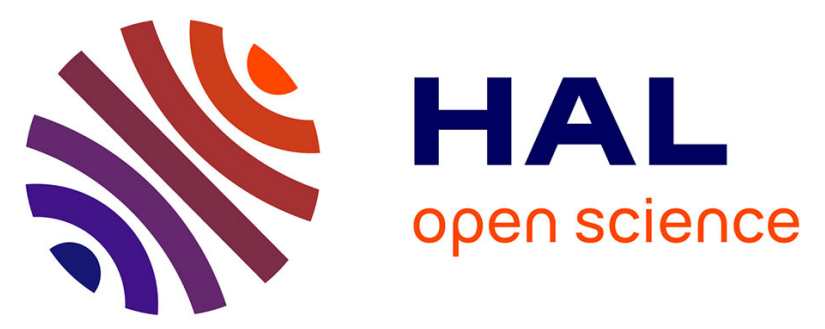

\title{
326 (PB-121) - Mammography screening among women living in Reunion Island (South Indian Ocean)
}

Rajae Touzani, Marc Karim Bendiane, Emmanuel Chirpaz, Anne-Déborah

Bouhnik, Léa Bruneau, Julien Mancini, Laetitia Huiart

\section{To cite this version:}

Rajae Touzani, Marc Karim Bendiane, Emmanuel Chirpaz, Anne-Déborah Bouhnik, Léa Bruneau, et al.. 326 (PB-121) - Mammography screening among women living in Reunion Island (South Indian Ocean). THE 11TH EUROPEAN BREAST CANCER CONFERENCE, Mar 2018, 21-23 March 2018

- Barcelona, Spain, Spain. 92 (3), pp.S90, 2018, Abstracts, EBCC 11 - Poster Session (Thursday, 22 March 2018). 10.1016/S0959-8049(18)30499-4 . inserm-02083742

\section{HAL Id: inserm-02083742 https://www.hal.inserm.fr/inserm-02083742}

Submitted on 29 Mar 2019

HAL is a multi-disciplinary open access archive for the deposit and dissemination of scientific research documents, whether they are published or not. The documents may come from teaching and research institutions in France or abroad, or from public or private research centers.
L'archive ouverte pluridisciplinaire HAL, est destinée au dépôt et à la diffusion de documents scientifiques de niveau recherche, publiés ou non, émanant des établissements d'enseignement et de recherche français ou étrangers, des laboratoires publics ou privés. 
when the sensitivity of DBT is over $80 \%$. However, DBT would only be costeffective if the sensitivity is greater than $90 \%$. Besides, DBT for the whole population is not cost-effective in the range of sensitivity and specificity reported in the literature.

Conclusion: In the range of sensitivity and specificity reported in literature, DBT would not be cost-effective in national breast cancer screening compared with DM unless the willingness to pay will increase to $€ 22,906$ per LYG at the current price level of DBT.

No conflict of interest

325 (PB-120)

Management of early breast cancer in Tunisia

Poster

M. Hadoussa ${ }^{1}$, J. Ayari ${ }^{1}$, M. Balti ${ }^{1}$, N. Hadoussa ${ }^{1}$, S. Ben Nasr ${ }^{1}$, A. Zribi ${ }^{1}$, S. Fendri ${ }^{1}$, K. Bouzaidi ${ }^{2}$, A. Haddaoui ${ }^{1}$. ${ }^{1}$ Military Hospital of Tunis, Medical Oncology Department, Tunis, Tunisia; ${ }^{2}$ Department of Radiology, Mohamed Tahar Maamouri University Hospital, Nabeul, Tunisia

Background: Breast cancer is the most frequent cancer among women accounting for almost 1.4 million worldwide. The incidence in Tunisia is approximately $35,1 / 100000$ according to the Northern-Tunisia Cancer Registry 2007-2009. However, early breast cancer (EBC) remains a rare entity in developing countries. The aim of this study was to describe the epidemiological, clinical, pathological and therapeutic characteristics of EBC among the tunisian population as well as the outcomes of its management.

Materials and Methods: This retrospective study involved 61 women treated for EBC in the medical oncology department of the Military Hospital of Tunis over a period of 38 months between June 2013 and July 2016.

Results: The average age was 55 years and $11.5 \%$ were younger than 40 years. Mammography was performed in all cases. Screening was inaugura in $20.7 \%$. Invasive ductal carcinoma was the most common histological type accounting for $83.6 \%$. The tumor had grade II SBR in $56 \%$. Lynph node invasion was observed in $64 \%$ of cases. Radical mastectomy (RM) was achieved in $73.8 \%$ of patient while breast-conservative surgery (CS) in only $26.2 \%$. Radiotherapy and chemotherapy was performed in $90 \%$ and $93.4 \%$ respectively. For a median follow up of 20 months, the overall survival (0S) was $100 \%$ for 1 year and $91.9 \%$ for 2 years. Disease-free survival (DFS) was respectively $96.2 \%$ and $93.8 \%$. In our study, OS was significantly correlated with SBR grade but not with others Known prognostic factors. Furthermore patients treated with CS had a 2-year OS better than those treated with RM $(100 \%$ versus $83.3 \%)$, but DFS was similar in both subgroups when we adapted minimal or maximalist attitude in the follow-up.

Conclusion: Prognosis of EBC is excellent. Screening mammography is highly recommended. It should be generalized in developing countries in order to reduce breast cancer mortality and morbidity. Treatment should be multidisciplinary and follow-up minimalist. Future trials may define the optimal management strategies for these tumors with the least cost.

No conflict of interest

326 (PB-121)

Poster

Mammography screening among women living in Reunion Island (South Indian Ocean)

T. Rajae $^{1}$, M.K. Bendiane ${ }^{2}$, E. Chirpaz ${ }^{3}$, A.D. Bouhnik ${ }^{1}$, L. Bruneau ${ }^{4}$, J. Mancini ${ }^{5}$, L. Huiart ${ }^{3} .{ }^{1}$ Aix Marseille Univ.- INSERM- IRD- SESSTIMEconomics \& Social Sciences Applied to Health \& Analysis of Medical Information- Marseille- France, Marseille, Marseille, France; ${ }^{2} \mathrm{ORS}$, Marseille, Marseille, France: ${ }^{3} \mathrm{CHU}$ de la Réunion- Unité de Soutien Méthodologique- Saint Denis- France, Reunion, Reunion, France; ${ }^{4} \mathrm{CHU}$ de la Réunion-INSERM- CIC 1410- Saint-Pierre-France, Reunion, Reunion, France; ${ }^{5}$ APHM- Hôpital de la Timone- Service Biostatistique et Technologies de l'Information et de la Communication-Marseille- France, Marseille, Marseille, France

Context: Reunion Island is an overseas French department with a large proportion of young people, higher than in the metropolitan territory. It is also noteworthy that there is a high proportion of single parents and of early childbearing. The unemployment rate was estimated at $29 \%$ in 2013 versus a national rate of $10 \%$. By contrast with other French overseas territories, the population of the Reunion island is very cosmopolite with eight major ethnic groups (from India, China, Africa, Comoros, Mayotte, Madagascar) and four religions (Muslims, Christians, Buddhists, and Hindus).

In this context, it is important to describe health behaviors of this French population, especially cancer screening practices to face the current lack of data.

The objective of this study is to describe the coverage of breast cancer screening with mammography among women aged 25-65 years living in Reunion Island.
Materiel and methods: A cross sectional survey has been conducted by phone questionnaire to 1000 women aged 25-65. Question on use of screening mammography was asked to all respondents. Univariate and multivariate statistical analyses have been performed to identify the associated factors with mammography use during the two previous years.

Results: Among women included in the survey, $33.9 \%$ have done a mammography during the past two years, $20.9 \%$ have done a mammography more than two years ago and $45.2 \%$ have never done a mammography. Among the 417 women aged from 50 to 65 years (i.e. those concerned by the organized breast cancer screening every two years), when comparing those who have done a mammography during the two past years $(63,9 \%)$ to the others $(36,1 \%)$, associated factors found were: reporting a low income, and/or a low literacy level, reporting a regular gynecologic follow-up, and having done a vaginal smear in the past two years (as recommended by medical authorities)

Conclusions: Social inequalities are major in Reunion Island and directly affect health behavior such as breast cancer screening by mammography. Public Policy have to be implemented in Reunion Island to promote specific action toward low income women, especially health education to increase health literacy.

No conflict of interest

327 (PB-122)

Poster

Cost of breast cancer opportunistic screening and trends in mammography coverage within the Brazilian National Health Service between 2008 and 2016

R. De Freitas Junior $^{1}$, D.C. Netto-Rodrigues ${ }^{1}$, R.M. Rahal ${ }^{1}$, R.S. Correa ${ }^{2}$ P.A. Gouveia ${ }^{1}$, E. Martins ${ }^{1}$, J.E. Peixoto ${ }^{3}$. ${ }^{1}$ Federal University of Goias, CORA Centro Avançado de Diagnóstico da Mama- Mastology ProgramHospital das Clínicas, Goiania, Brazil; ${ }^{2}$ National Nuclear Energy Commission CNEN, Midwestern Regional Center of Nuclear Sciences, Abadia de Goias, Brazil; ${ }^{3}$ National Cancer Institute INCA- Brazil, lonizing Radiation Quality Control Service, Rio de Janeiro, Brazil; On behalf of brazilian mastology research network

Purpose: To evaluate breast cancer screening costs and coverage within the Brazilian National Health System (SUS) in the country's regions, states and Federal District during 2008-2016.

Methods: An ecological time series analyzing breast cancer screening within the SUS in women aged 50-69 years. Coverage was calculated from the ratio of the number of mammograms conducted and the expected number for the target population. Joinpoint regression analysis was used to calculate annual percent changes (APC) in coverage.

Results: Around 19 million mammograms were performed in 50-69-year old women within the SUS during 2008-2016 at an approximate cost of US $\$ 260$ million. Coverage increased nationwide in 2008-2012, remaining stable thereafter. Regionally, only in the northeast did coverage increase throughout the entire study period, while in the south coverage initially increased, then fell, and in the north, southeast and Midwest, coverage increased, then stabilized. Coverage increased significantly in $8 / 26$ states (31\%) during the period and stabilized in $5(19 \%)$. In 12 states $(46 \%)$, an initial increase preceded stabilization in $11(92 \%)$ and a reduction in coverage in $1(0.8 \%)$. In another state coverage initially stabilized, increasing thereafter. In the Federal District, the APC initially stabilized, then decreased.

Conclusion: Time-trend analysis showed that mammography coverage within the Brazilian SUS doubled, possibly indicating that public policies were effective albeit insufficient for the organized screening recommended by the World Health Organization. Growth differed between regions and states, with a tendency for this situation to worsen, as highlighted by the APC for the final 4-year period, showing stabilization.

No conflict of interest

\section{Thursday, 22 March 2018}

\section{POSTER SESSION Systemic Treatment}

328 (PB-123)

Impact of special subpopulations of breast cancer on survival in Egyptian patients : Breast Gynaecology International Cancer Society (BGICS) study

H. Elghazaly ${ }^{1,2}$, M. Kamal ${ }^{1}$, A. Nagy ${ }^{1}$, S. Zaki ${ }^{1}$, G. Elshaarany ${ }^{3}$, N. Elwasly ${ }^{1}$ A. Gaballah ${ }^{1}$, M. Hany ${ }^{4}$, Z. Eldaly ${ }^{5}$, S. Nigm ${ }^{6}$, A. Elkholy ${ }^{7}$, Y. Abugabal ${ }^{8}$. 